\title{
NOVOS AGONISTAS DOPAMINÉRGICOS
}

\author{
JAMES PITÁGORAS DE MATTOS* VÂNIA MARIA DE B. CORREA MATTOS**
}

\begin{abstract}
RESUMO - Apresentamos breve revisão da literatura sobre os agonistas dopaminérgicos. Referimos os cinco receptores conhecidos e onde estão localizados, as vantagens e as desvantagens de sua utilização nos pacientes com a doença de Parkinson.Introduzidos com o objetivo principal de controlar as limitações da levodopa, aumentando a janela terapêutica, analisamos a farmacocinética, a eficácia e os efeitos colaterais da cabergolina, do ropinirole e do pramipexole.
\end{abstract}

PALAVRAS-CHAVE: levodopa, agonistas dopaminérgicos, doença de Parkinson.

\section{New dopaminergic agonists}

ABSTRACT - We present a brief review of the literature about dopaminergic agonists. We report the five known dopaminergic receptors, where they are located, the advantages and disadvantages of the employment in parkinsonian patients. The dopaminergic agonists were introduced to control the limitations of levodopa-increasing the therapheutic window. We analyse the pharmacocynetic efficacy and the side effects of cabergoline, ropinirole and pramipexole.

KEY WORDS: levodopa, dopaminergic agonists, Parkinson's disease.

Na prática neurológica, o tratamento da doença de Parkinson é marcado por uma série de controvérsias, tanto no emprego de medicamentos, quanto nas indicações e nos resultados cirúrgicos. No que se refere ao emprego de medicamentos, no entanto, há algumas observações consideradas não controversas, ou seja, situações de unanimidade. Uma dessas aceitas por todos é a de que a levodopa continua sendo o agente farmacológico sintomático mais eficaz. Uma vez iniciada a levodopaterapia, porém, passamos a conviver com dois fantasmas que podem aparecer em algum momento: o declínio da eficácia terapêutica e os efeitos colaterais, tais como, as flutuações motoras, as discinesias e os distúrbios neuro-psiquiátricos. Essas complicações, entre outras, são muito comuns no tratamento a longo prazo. Com o objetivo principal de superar ou controlar as limitações da levodopaterapia, foram introduzidos originariamente os agonistas dopaminérgicos ${ }^{1-6}$.

Precedendo a apresentação dos novos agonistas veremos o que são agonistas dopaminérgicos, quais são os receptores dopaminnérgicos até agora conhecidos, onde estão anatomicamente localizados e quais as vantagens e as desvantagens da sua utilização no tratamento da doença de Parkinson.

Agonistas dopaminérgicos são drogas que estimulam diretamente os receptores pós-sinápticos da dopamina, aumentando a eficácia terapêutica da levodopa ${ }^{1,2,4-6}$.

Técnicas modernas de biologia molecular permitiram conhecer, até o presente momento, cinco tipos de receptores dopaminérgicos: $\mathrm{D}_{1}, \mathrm{D}_{2}, \mathrm{D}_{3}, \mathrm{D}_{4}$ e $\mathrm{D}_{5}$. Esses receptores estão organizados em dois grupos: o grupo $\mathrm{D}_{1}$ ou $\mathrm{D}_{1}$-like e o grupo $\mathrm{D}_{2}$ ou $\mathrm{D}_{2}$-like. $\mathrm{O}$ grupo $\mathrm{D}_{1}$ está representado pelos receptores $\mathrm{D}_{1}$ e $\mathrm{D}_{5}$; o grupo $\mathrm{D}_{2}$, pelos receptores $\mathrm{D}_{2}, \mathrm{D}_{3}$ e $\mathrm{D}_{4}$. A definição desses dois grupos está

Serviço de Neurologia do Hospital Universitário Clementino Fraga Filho da Universidade Federal do Rio de Janeiro (UFRJ) (Chefia:Prof. Sérgio Novis); *Professor Adjunto e Chefe do Setor de Distúrbios do Movimento; **Neurologista. Aceite: 9-dezembro-1998.

Dr. James Pitágoras de Mattos- Av. São Sebastião 165/SS101 - 22291-070 Rio de Janeiro RJ -Brasil. 
Tabela 1. Localizações anatômicas principais dos receptores dopaminérgicos dos grupos $D_{1}\left(D_{1} e D_{5}\right)$ e $D_{2}\left(D_{2}, D\right.$, e $\left.D_{4}\right)$.

\begin{tabular}{ll}
\hline Receptores & Localizações anatômicas \\
\hline $\mathrm{D}_{1}$ & Caudado, putamen, accumbens e trato olfativo. \\
$\mathrm{D}_{5}$ & Hipocampo e hipotálamo. \\
$\mathrm{D}_{2}$ & Caudado, putamen, accumbens e trato olfativo. \\
$\mathrm{D}_{3}$ & Áreas límbicas, trato olfativo, accumbens, ilhas Calleja e hipotálamo. \\
$\mathrm{D}_{4}$ & Córtex frontal, hipocampo e accumbens. \\
\hline
\end{tabular}

baseada na ligação com os mecanismos de transdução. Os pertencentes ao grupo $\mathrm{D}_{1}$, estimulam a enzima adenilato ciclase e aumentam o nível intracelular de AMP cíclico enquanto os do grupo $\mathrm{D}_{2}$ inibem essa enzima e diminuem o AMP cíclico intracelular ${ }^{2,5,7,8}$.

Os receptores dopaminérgicos estão distribuídos anatomicamente em áreas ditas principais ou de alta densidade (Tabela 1). Devido à localização principal de $\mathrm{D}_{1}$ e de $\mathrm{D}_{2}$ no núcleo caudado, no putamen e no núcleo accumbens, acredita-se que esses receptores exerçam um papel no comportamento motor. Assim, a regra geral é de que estimulando os receptores $\mathrm{D}_{1}$ e $\mathrm{D}_{2}$ (ação agonista) ocorra efeito antiparkinsoniano. A maioria dos agonistas dopaminérgicos, eficazes como antiparkinsonianos, atuam no receptor $\mathrm{D}_{2}$ (em animais e em humanos) $)^{2,5,7-9}$.

As principais vantagens da utilização dos agonistas dopaminérgicos são as seguintes : 1- retarda-se, pelo menos por um ano, o uso da levodopa, e, por consequência, a produção de radicais livres geradores do estresse oxidativo, tendo em vista a tendência atual de usar os agonistas inicialmente sob a forma de monoterapia;

2- aumenta a eficácia antiparkinsoniana em pacientes em uso de levodopa;

3- a maioria dos agonistas tem meia-vida longa podendo ser administrado em três doses diárias;

4- não geram radicais livres;

5- vários estudos têm demonstrado a possível ação neuroprotetora;

6- o risco de desenvolverem discinesias ou flutuações motoras é bem menor, quando comparado com a levodopa, além de, como terapia adjunta, diminuir ou atenuar as flutuações motoras ${ }^{2,4,6}$.

As principais desvantagens são:

1- menos eficazes do que a levodopa;

2- mais difíceis de serem tolerados, mormente pelos distúrbios na esfera mental (alucinações, delírios e confusão mental $)^{2,4,6}$.

Os principais fármacos atualmente disponíveis são a apomorfina, a bromocriptina, o lisuride e o pergolide. Desses, a bromocriptina e o pergolide são os mais utilizados. A maioria dos estudos comparativos entre o pergolide e a bromocriptina demonstra a eficácia de ambos em aumentar o número de horas on e em diminuir os estados off, em reduzir as flutuações motoras e em reduzir as doses de levodopa (30\% em média). Nesses estudos comprovou-se a ligeira maior eficácia do pergolide, até porque é agonista de $\mathrm{D}_{1}$ e de $\mathrm{D}_{2}$, enquanto a bromocriptina é agonista de $\mathrm{D}_{2}$ e antagonista de $\mathrm{D}_{1}$. Entretanto, devido a heterogeneidade das metodologias empregadas nos estudos, esses resultados devem ser analisados com reservas ${ }^{6}$. A dose média empregada do pergolide é de 1-2 mg/ dia e a da bromocriptina de $15-20 \mathrm{mg} / \mathrm{dia}$, como terapia adjunta a levodopa. Os efeitos colaterais decorrem da estimulação dopaminérgica central ou periférica, sendo mais frequentes náuseas, tonteiras, sonolência, hipotensão ortostática, alucinações, deliríos, confusão mental e discinesias. A bromocriptina e o pergolide, por serem ergolíneos, podem causar raros, porém sérios, efeitos adversos, tais como, edema dos membros inferiores, fenômeno de Raynaud, eritromelalgia e fibroses 
pleuropulmonar e retroperitoneal ${ }^{6}$. Em um grupo de pacientes parkinsonianos que utilizou o pergolide como terapia adjunta com a levodopa, Jankovic ${ }^{10}$, em 1992, observou a ocorrência dos seguintes efeitos adversos e que, posteriormente, poderão servir comparativamente para serem cotejados com os novos agonistas: aumento das discinesias em $62 \%$, náuseas em $24 \%$, alucinações em $14 \%$, rinite em $12 \%$, sonolência em $10 \%$ e hipotensão postural em $9 \%$.

Passemos agora, a analisar os três novos agonistas dopaminérgicos (a cabergolina, o ropinirole e o pramipexole ) que, em breve, estarão disponíveis em nosso meio. Em separado, veremos a estrutura química, a afinidade quanto ao receptor, a farmacocinética, a eficácia e os seus efeitos colaterais.

\section{Cabergolina}

A cabergolina é agonista ergolíneo com afinidade para $\mathrm{D}_{2}$. Chama a atenção a sua meia vida muito longa, maior do que 24 horas, o que permite a administração em dose única diária. Essa costuma ficar entre 2,5 e 5,0 mg/dia. É considerada eficaz como tratamento adjunto na doença de Parkinson, melhorando em aproximadamente $30 \%$ as incapacidades motoras, quando acompanhados pela escala UPDRS (Unified Parkinson Disease Rating Scale). Os efeitos colaterais são semelhantes aos ergolíneos. Doses acima de 10mg costumam levar a alucinações e à hipotensão postural. Após 5 anos de tratamento, Rinne e col. ${ }^{11}$ observaram que a ocorrência de complicações motoras (discinesias e flutuações) foi bem menos frequente que as induzidas pela levodopa. A grande desvantagem é o seu alto custo ${ }^{11,12}$.

\section{Ropinirole}

É um novo agonista dopaminérgico, porém, não-ergolíneo, que atua seletivamente em $\mathrm{D}_{2}$ com alta afinidade(+++); não tem afinidade por $\mathrm{D}_{1}$ (Tabela 2). A dose recomendada é 1,5 - 8,0 mg/ dia, em três tomadas, pois tem também meia-vida relativamente longa. Empregado em monoterapia, demonstrou-se eficaz no controle das incapacidades motoras em $24 \%$, quando comparados com o basal.Quando comparados com a levodopa, os resultados indicaram eficácia similar em parkinsonianos na fase inicial.Os efeitos colaterais mais comuns foram náuseas, vômitos, tonteiras, sonolência, cefáleia, hipotensão postural e aumento das discinesias. As alucinações ocorreram em somente 2,6\% dos pacientes. A expectativa é de que as fibroses pulmonar e retroperitoneal, assim como os efeitos vasculares, sejam bem menos frequentes, por não ser ergolíneo ${ }^{12-14}$.

\section{Pramipexole}

É um novo agonista dopaminérgico também não ergolíneo; quimicamente é um derivado benzotiazólico. Exibe alta afinidade pelos receptores $\mathrm{D}_{3}$ localizados em áreas mesolímbicas,

Tabela 2. Afinidade dos agonistas dopaminérgicos ergolíneos e não-ergolíneos.

\begin{tabular}{lll}
\hline Agonistas dopaminérgicos & \multicolumn{2}{l}{ Especificidade do receptor } \\
\hline & $\mathrm{D}_{1}$ & $\mathrm{D}_{2}$ \\
Apomorfina & + & +++ \\
Bromocriptina & - & ++ \\
Lisuride & - & +++ \\
Pergolide & + & +++ \\
Cabergolina & + & +++ \\
Ropinirole & 0 & +++ \\
Pramipexole & 0 & +++ \\
\hline
\end{tabular}

0, não afinidade; +, agonista com baixa afinidade; -, antagonista; +++, agonista com alta afinidade. 
resultando, também, em ação antidepressiva. São apresentados em comprimidos de 0,125, de 0,25, de 1,0 e de $1,5 \mathrm{mg}$. A dose média diária recomendada varia de 1,5 a 4,5mg. A sua meia-vida é relativamente longa, 9-12 horas, podendo ser usado, portanto, em três tomadas diárias. A biodisponibilidade é $90 \%$. A sua eficácia foi comprovada em, praticamente, todos os estudos, sendo que, quando em monoterapia, evidenciou melhora em aproximadamente $30 \%$ nas atividades da vida diária pelos escores da UPDRS. Os principais efeitos colaterais foram: náuseas, insônia, sonolência, constipação intestinal, fadiga e alucinações, entre outros menos frequentes.Segundo publicação recente de Shannon e col., após avaliarem 335 pacientes em monoterapia por 6 meses, com dose média de 3,8mg/dia, foram os seguintes os principais efeitos adversos: náuseas (39\%), insônia (25\%), sonolência $(18,3 \%)$, constipação intestinal $(17,7 \%)$ e alucinações $(11,5 \%)^{12,15,16}$.

\section{CONCLUSÕES}

1. Os agonistas dopaminérgicos foram introduzidos para controlar as limitações da levodopaterapia, melhorando as incapacidades motoras em 20-30\% nos seus escores.

2. A tendência moderna é começar o tratamento da doença de Parkinson com os agonistas dopaminérgicos em monoterapia, retardando, assim, o uso da levodopa.

3. Quando utilizados em monoterapia, raramente produzem flutuações motoras e discinesias.

4. Os agonistas não-ergolíneos como o ropinirole e o pramipexole foram desenvolvidos para serem mais eficazes e determinarem menos efeitos colaterais, sobretudo os da esfera mental quando comparados com os ergolíneos, como a bromocriptina e o pergolide, o que somente no futuro saberemos.

\section{REFERÊNCIAS}

1. Poewe W, Caraceni T. Dopamine agonists in the treatment of Parkinson's disease. Neurology 1995;45(Suppl 3):S5.

2. Jenner P. The rationale for the use of dopamine agonist in Parkinson's disease. Neurology 1995;45(Suppl 3):S6-S12.

3. Mizuno Y, Kondo T, Narabayashi H. Pergolide in the treatment of Parkinson's disease. Neurology 1995;45(Suppl 3):S13-S21.

4. Wolters E, Tissingh G, Bergmans PLM, Kuiper MA. Dopamine agonists in Parkinson's disease. Neurology 1995;45 (Suppl 3):S28-S34.

5. Watts RL. The role of dopamine agonists in the early Parkinson's disease.Neurology 1997;49(Suppl 1):S34-S48.

6. Barbosa ER. Tratamento medicamentoso da doença de Parkinson. In Meneses MS, Teive HAG (eds). Doença de Parkinson: aspectos clínicos e cirúrgicos. Rio de Janeiro:Guanabara Koogan, 1996;97-110.

7. Sibley DR, Monsma FJ Jr. Molecular biology of dopamine receptors. Trends Pharmacol Sci 1992;13,61-69.

8. Wolters EC. The role of D1 and D2 dopamine receptors in motor behavior of patients with Parkinson's disease. Eur J Neurol 1996;3 (Suppl 1):19-24.

9. Seelman P. Dopamine receptors and psychosis. Scientific Amer 1995;(Sept./Oct.) 28-37.

10. Jankovic J. Pergolide:clinical experience. In Agyd Y. Current Trends in the treatment of Parkinson's disease. London:John Libbey, 1992:93-103.

11. Rinne UK, Bravo F, Chouza C, et al.. Early treatment of Parkinson's disease with cabergoline delays the onset of motor complications: results of a double-blind, L-dopa controled trial. Mov Disord 1997;12(Suppl 1):64.

12. Barbosa ER. Avanços terapêuticos na doença de Parkinson. In Nitrini R, Yacubian EMT, Rabelo GD e Machado LR (eds). Condutas em neurologia, São Paulo:Clínica Neurológica HC/ FMUSP, 1997:241-246.

13. Stern MB. Contemporary approaches to the pharmacotherapeutic management of Parkinson's disease: an overview. Neurology 1997:49(Suppl 1):S2-S9.

14. Tulloch IF. Pharmacologic profile of ropinirole: a nonergoline dopamine agonist. Neurology 1997;49(Suppl 1):S58-S62.

15. Parkinson study group. Safety and efficacy of pramipexole in early Parkinson's disease: a randomized dose-rating study. JAMA 1997;278:125-130.

16. Shannon KM, Bennett JP Jr, Friedman JH. Efficacy of pramipexole, a novel dopamine agonist, as monotherapy in mild to moderate Parkinson's disease. Neurology 1997;49:724-728. 